\title{
QM/MM Study of the Catalytic Cycle of Water Splitting in Photosystem II
}

\author{
Eduardo M. Sproviero, José A. Gascón, James P. McEvoy, \\ Gary W. Brudvig, and Victor S. Batista * \\ Department of Chemistry, Yale University, P.O.Box 208107, New Haven, CT 06520-8107, U.S.A.
}

\section{Supporting Information}

\section{Contents}

1. Comparative analysis of mechanistic models discussed in Sec. 3.5 of the main paper.

2. Complete reference 36 .

3. References of the supporting information.

\section{Comparative Analysis of Mechanistic Models Discussed in Sec. 3.5 of the main paper}

The DFT-QM/MM proposal for the catalytic cycle of water-splitting, introduced in Sec.3.2 of the main paper, includes several aspects common to previously proposed mechanisms

*To whom correspondence should be addressed. Email: victor.batista@yale.edu 
(see Ref. 1 for a review) as well as significant differences. Figures 10-14 of the main paper show the detailed structural and electronic rearrangements as compared to models recently proposed by Siegbahn,, ${ }^{2,3}$ Messinger ${ }^{4}$ and Brudvig. ${ }^{5,6}$

In accordance with experiments conducted on various PSII preparations and inorganic model compounds, the oxidizing power of the OEC is predicted to accumulate in the $\mathrm{Mn}$ ions of the metal complex. ${ }^{7,8}$ This aspect, however, disagrees with other proposals where oxidation involves species near the cluster, ${ }^{9,10}$ or perhaps a manganese-bridging oxo group. ${ }^{11}$ Second, in agreement with previous work, ${ }^{12,13}$ the formation of an oxyl-radical associated with $\mathrm{Mn}(4)$ in the $\mathrm{S}_{4}$ state is found to be essential for the $\mathrm{O}=\mathrm{O}$ bond formation, although in other proposed mechanisms the constituent atoms of dioxygen come from manganesebound terminal water molecule deprotonated by basic $\mu$-oxo ligands,${ }^{14}$ or from manganesebridging oxo-ligands that react with one another during the $\mathrm{O}=\mathrm{O}$ bond forming step. ${ }^{15,16}$

Several differences can be noted when comparing the DFT-QM/MM structures for the $\mathrm{S}_{0} \rightarrow \mathrm{S}_{1}$ transition (Figure 10 of the main paper) to other proposals, including the detailed ligation scheme, structural rearrangements and changes in oxidation and protonation states. Starting the comparison with the structures proposed by Siegbhan, ${ }^{2,3}$ the main differences are (see Figures $10(a)$ and (b) of the main paper):

$\mathbf{S}_{0}$ state:

1. Protonation state of the $\mathrm{O}$ linked to $\mathrm{Ca}, \mathrm{Mn}(1)$, and $\mathrm{Mn}(3)$ in (b).

2. Missing $\mu$-oxo bridge between $\mathrm{Mn}(4)-\mathrm{Mn}(3)$ in (b) while there is a protonated bridge in (a).

3. E333 is ligated to $\mathrm{Mn}(4)$ in (b) while it is ligated to both $\mathrm{Mn}(2)$ and $M n(3)$ in (a). 
4. Ca has three water ligands in (b) while one in (a).

5. $\mathrm{HCO}_{3}^{-}$bridging $\mathrm{Ca}$ and $\mathrm{Mn}(4)$ in (b) is replaced by two water molecules in (a).

6. E189 bridging between $\mathrm{Ca}$ and $\mathrm{Mn}(2)$ in (b) is not bridging in (a).

7. $\mathrm{H}_{2} \mathrm{O}$ ligand to $\mathrm{Ca}$ in (b) is $\mathrm{Cl}^{-}$in (a).

8. A344 is not ligated to Ca in(b) while it is in (a).

9. $\mathrm{Mn}(3)$ has an extra water ligand in (b).

10. $\mathrm{OH}$ ligand to $\mathrm{Mn}(4)$ in (b) is $\mathrm{H}_{2} \mathrm{O}$ in (a).

11. OH ligated to $\mathrm{Mn}(1)$ in (b) is $\mathrm{H}_{2} \mathrm{O}$ in (a).

$\mathbf{S}_{0} \rightarrow \mathbf{S}_{1}$ transition:

1. Oxidization of $M n(3)$ in (b) versus oxidization of $M n(2)$ in (a).

2. Deprotonation of $\mathrm{HO}$ linked to $\mathrm{Ca}, \mathrm{Mn}(1)$ and $\mathrm{Mn}(3)$ in (b) while deprotonation of a $\mathrm{H}_{2} \mathrm{O}$ ligand to $\mathrm{Mn}(4)$ in (a).

3. Different changes in Mn-Mn distances.

4. No opening of a $\mu$-oxo bridge between $\mathrm{Mn}(4)$ and $\mathrm{Mn}(3)$, suggested by (a).

5. No entering of $\mathbf{W}^{\text {fast }}$, suggested by (a). 
Several differences can also be noted when comparing the DFT-QM/MM structures for the $\mathrm{S}_{0} \rightarrow \mathrm{S}_{1}$ transition to the structures proposed by Messinger. ${ }^{4}$ The main differences are: (see Figures 10 (a) and (c) of the main paper)

$\mathbf{S}_{0}$ state:

1. $\mu$-oxo bridge between $\mathrm{Mn}(4)-\mathrm{Mn}(3)$ is not protonated in (c).

2. Protonated state of the $\mathrm{O}$ linked to $\mathrm{Ca}, \mathrm{Mn}(2)$ and $\mathrm{Mn}(3)$ in (c).

3. Missing bond between $\mathrm{Mn}(4)$ and the cuboidal $\mathrm{O}$ linked to $\mathrm{Mn}(2), \mathrm{Mn}(3)$ and $\mathrm{Ca}$ ) in (c).

4. $\mathrm{HCO}_{3}^{-}$bridging $\mathrm{Mn}(4)$ and $\mathrm{Ca}$ in (c) is replaced by two water molecules in (a).

5. $\mathrm{W}^{\text {slow }}$ in (c) involves an $\mathrm{OH}$ of the cuboid coordinated to $\mathrm{Mn}$ ions.

6. E333 is ligated to $\mathrm{Mn}(4)$ in (c) while it is ligated to both $\mathrm{Mn}(2)$ and $\mathrm{Mn}(3)$ in (a).

7. $\mathrm{Mn}(3)$ has an extra water ligand in (c).

8. W ligated to Ca in (c) is A344 in (a).

$\mathbf{S}_{0} \rightarrow \mathbf{S}_{1}:$

1. Deprotonation of $\mathrm{HO}$ linked to $\mathrm{Ca}, \mathrm{Mn}(2)$ and $\mathrm{Mn}(3)$ in (c) while deprotonation of a $\mathrm{H}_{2} \mathrm{O}$ ligand to $\mathrm{Mn}(4)$ in (a).

2. No opening of the bridge between $\mathrm{Mn}(4)$ and $\mathrm{Mn}(3)$ in (c) while suggested in (a).

3. No entering of $\mathbf{W}^{\text {fast }}$ in (c) while suggested in (a). 
Figure 10(d) (main paper) shows the $S_{0} \rightarrow S_{1}$ transition proposed by Brudvig and coworkers. ${ }^{5,6}$ The main differences are:

$\mathbf{S}_{0}$ state:

1. Oxidation state $\mathrm{S}_{0}(\mathrm{IV}, \mathrm{IV}, \mathrm{III}, \mathrm{II})$ in (d) versus $\mathrm{S}_{0}(\mathrm{IV}, \mathrm{III}, \mathrm{III}, \mathrm{III})$ in (a).

2. A344 involves bidentated coordination to $\mathrm{Ca}$ in (d) while monodentated in (a).

3. No $\mu$-oxo bridge between $\mathrm{Mn}(3)$ and $\mathrm{Mn}(4)$ in (d).

4. $\mathrm{W}^{\text {fast }}$ is already ligated to $\mathrm{Mn}(4)$ in (d).

5. E333 ligated to $\mathrm{Mn}(4)$ in (d).

6. $\mathrm{Mn}(3)$ is not ligated to $\mathrm{Mn}(4)$ in (d)

7. $M n(3)$ has an extra water ligand in (d).

$\mathbf{S}_{0} \rightarrow \mathbf{S}_{1}$ transition:

1. Oxidation of $M n(4)$ in(d) while oxidation of $M n(2)$ in (a).

2. No opening of the bridge between $M n(4)$ and $M n(3)$ in (d) while suggested in (a).

3. No entering of $\mathbf{W}^{\text {fast }}$ in (c) while suggested in (a).

Figure 11 (main paper) shows the analogous comparison between the $S_{1} \rightarrow S_{2}$ transition proposed by the DFT-QM/MM structural models and the corresponding structures and rearrangements suggested by other proposals. Starting the comparison with the structures proposed by Siegbahn, ${ }^{2,3}$ the main differences are: (see Figures 11 (a) and (b) of the main paper) 
1. Oxidation of $M n(2)$ in (b) versus oxidation of $M n(3)$ in (a).

2. Proton transfer between water and $\mathrm{OH}$ ligands to $\mathrm{Mn}(3)$ in (b) not observed in (a).

The main differences when comparing the DFT-QM/MM structures for the $S_{1} \rightarrow S_{2}$ transition to the structures proposed by Messinger ${ }^{4}$ are: (see Figures 11 (a) and (c) of the main paper)

1. Oxidation of $\mathrm{Mn}(4)$ in (c) versus oxidation of $\mathrm{Mn}(3)$ in (a). The resulting oxidation state is $\mathrm{S}_{2}(\mathrm{IV}, \mathrm{IV}, \mathrm{III}, \mathrm{IV})$ in (c) versus $\mathrm{S}_{2}(\mathrm{IV}, \mathrm{IV}, \mathrm{IV}, \mathrm{III})$ in (a).

2. Reorientation of $\mathrm{W}^{\text {fast }}$ ligated to $\mathrm{Mn}(4)$ in (c) not observed in (a).

3. Formation of a hydrogen bond with $\mathbf{W}^{\text {slow }}$ in (c) not observed in (a).

Figure 11(d) (main paper) shows that the $S_{1} \rightarrow S_{2}$ transition proposed by the DFT/QMMM structural models is equivalent to the transition proposed by Brudvig and coworkers, ${ }^{5,6}$ including oxidation of $\mathrm{Mn}(3)$ and no significant structural rearrangements.

The main difference when comparing the DFT-QM/MM structures for the $\mathrm{S}_{2} \rightarrow \mathrm{S}_{3}$ transition to the structures proposed by Siegbahn $n^{2,3}$ is in the mechanism forming the oxo-bridge between $\mathrm{Mn}(3)$ and $\mathrm{Mn}(4)$ (see Figures 12 (a) and (b) of the main paper). While (a) involves proton transfer to the $\mathrm{OH}$ ligand of $\mathrm{Mn}(4)$, (b) involves double deprotonation of a W ligand to $\mathrm{Mn}(3)$. One proton is transferred to an $\mathrm{OH}$ ligand of $\mathrm{Mn}(3)$ and the other proton is released to the lumen. In contrast, the proton that is released to the lumen in (a) comes from $\mathrm{W}^{\text {fast}}$, which is ligated to $\mathrm{Mn}(4)$. As mentioned in Sec. 3.2 of the main paper, the $\mathrm{S}_{2} \rightarrow \mathrm{S}_{3}$ transition also reorients the substrate water molecules inducing hydrogen bonding between 
$\mathrm{W}^{\text {fast }}$ and CP43-R357 as well as hydrogen bonding between $\mathrm{W}^{\text {slow }}$ and the newly formed oxo-bridge between $\mathrm{Mn}(3)$ and $\mathrm{Mn}(4)$.

Similarly to previous intermediate structures there are several differences when comparing the resulting $S_{3}$ state proposed by the DFT-QM/MM structures (see Figure 12(a) of the main paper) and the structure proposed by Siegbahn ${ }^{2,3}$ (see Figure 12(b) of the main paper) are:

1. The $\mathrm{OH}$ ligand to $\mathrm{Mn}(4)$ in (b) is $\mathrm{W}$ in (a).

2. E333 is ligated to $M n(4)$ in (b) but ligated to $M n(2)$ and $M n(3)$ in (a).

3. W ligand to $\mathrm{Mn}(3)$ in (b) is the carboxylate group of E333 in (a).

4. $\mathrm{HCO}_{3}^{-}$bridging $\mathrm{Mn}(4)$ and $\mathrm{Ca}$ in (b) is replaced by substrate water molecules in (a).

5. E189 is bridging between $\mathrm{Mn}(2)$ and $\mathrm{Ca}$ in (b) while is only ligated to $\mathrm{Mn}(2)$ in (a).

6. One of the water ligands to calcium in (b) is $\mathrm{Cl}^{-}$in (a).

7. A344 is not ligated to Ca in (b) while it is in (a).

The main differences when comparing the DFT-QM/MM structures for the $\mathrm{S}_{2} \rightarrow \mathrm{S}_{3}$ transition to the structures proposed by Messinger ${ }^{4}$ are: (see Figures 12 (a) and (c) of the main paper)

1. There is no oxidation of a Mn-center in (c) while $\mathrm{Mn}(4)$ is oxidized in (a).

2. An unpaired electron is localized on $\mathrm{O}(\mathrm{Ca}, \mathrm{Mn}(1), \mathrm{Mn}(2))$ in (c) while there is no unpaired electron at that oxo-bridge in (a). 
3. No structural rearrangements due to formation of an oxo-bridge between $\mathrm{Mn}(3)$ and $\mathrm{Mn}(4)$ in (c) since the bridge is already formed.

4. No proton transfer between ligands of $\mathrm{Mn}(3)$ and $\mathrm{Mn}(4)$ in (c) while there is in (a).

5. The hydrogen bond between $\mathrm{W}^{\text {slow }}$ and $\mathrm{W}^{\text {fast }}$ is broken in both (a) and (c). However, substrate water molecules form new hydrogen bonds in (a) and not in (c).

6. Different oxidation state $\mathrm{S}_{3}(\mathrm{IV}, \mathrm{IV}, \mathrm{III}, \mathrm{IV})$ with an oxygen radical in (c) while $\mathrm{S}_{3}(\mathrm{IV}$, IV, IV, IV) in (a).

7. The $\mathrm{OH}$ ligand $\left(\mathrm{W}^{\text {fast }}\right)$ and $\mathrm{HCO}_{3}^{-}$ligand to $\mathrm{Mn}(4)$ in (c) are $\mathrm{W}$ and $\mathrm{W}^{\text {fast }}$ in (a).

8. The ligands to $\mathrm{Ca}$ are different in (c) and (a).

The main difference between the $S_{2} \rightarrow S_{3}$ transition predicted by the DFT-QM/MM structures (Figure 12(a) of the main paper) and the transition proposed by Brudvig (Figure 12(d) of the main paper) is that there are no structural rearrangements due to oxo-bridge formation in (d) while an oxo-bridge is formed in (a). However, both transitions (a) and (d) involve oxidation of $\mathrm{Mn}(4)$, and have common oxidation numbers of the Mn-centers in the $\mathrm{S}_{2}$ and $\mathrm{S}_{3}$ states. The main differences in the $\mathrm{S}_{3}$ structure are:

1. Deprotonation of CP43-R357 in (d), while deprotonation of $\mathrm{W}^{\text {fast }}$ is proposed in (a).

2. An oxo-bridge between $M n(3)$ and $M n(4)$ is missing in (d).

3. E333 is ligated to $M n(2)$ and $M n(4)$ in (d) while ligated to $M n(2)$ and $M n(3)$ in (a).

4. The $\mathrm{OH}$ ligand to $\mathrm{Mn}(4)$ in (d) is $\mathrm{W}$ in (a). 
5. The ligands to $\mathrm{Ca}$ are different in (d) and (a).

Figure 13 of the main paper shows the comparison between the $S_{3} \rightarrow S_{4}$ transition proposed by the DFT-QM/MM structural models and the corresponding structures and molecular rearrangements suggested by other proposals. Starting the comparison with the structures proposed by Siegbahn,, ${ }^{2,3}$ the main differences are: (see Figures 13 (a) and (b) of the main paper)

1. Oxidation creates an Mn-oxyl radical bridging between $\mathrm{Ca}$ and $\mathrm{Mn}(4)$ in (b) while hydrogen bonded CP43-R357 in (a).

2. $\mathrm{HCO}^{-}$is detached from the cluster from the metal cluster in (b) while no such structural rearrangements are observed in (a).

3. Formation of an oxo-bridge between $\mathrm{Mn}(4)$ and $\mathrm{Ca}$ in (b) is not observed in (a).

4. A bond is broken between $\mathrm{Mn}(4)$ and $\mathrm{O}(\mathrm{Ca}, \mathrm{Mn}(2), \mathrm{Mn}(3))$ in (b) while is not broken in (a).

5. W ligand enters the OEC and becomes the sixth ligand of $\mathrm{Mn}(4)$ in (b), while no W molecule enters in (a).

6. Deprotonation of the $\mathrm{OEC}$ in (b) presumably results from decomposition of $\mathrm{HCO}_{3}^{-}$into an oxo radical, $\mathrm{CO}_{2}$, and $\mathrm{H}^{+}$while in (a) $\mathrm{W}^{\text {fast }}$ is deprotonated.

The main differences when comparing the $S_{3} \rightarrow S_{4}$ transition proposed by the DFTQM/MM structural models and the corresponding structures proposed by Messinger ${ }^{4}$ are: (see Figures 13 (a) and (c) of the main paper) 
1. A peroxidic intermediate is formed in (c) while an oxyl radical is formed in (a).

2. Hydrogen bonds between $\mathrm{W}^{\text {slow }}$ and the oxo-bridge between $\mathrm{Mn}(3)$ and $\mathrm{Mn}(4)$, and the oxyl radical and CP43-R357 are reinforced in (a) but not in (c).

The resulting DFT QM/MM model of the $S_{4}$ state is also significantly different from the model proposed by Messinger, ${ }^{4}$ including a different arrangement of ligands, as discussed for the analogous comparison in the $S_{3}$ state, and different oxidation states. Note that the oxidation states are $\mathrm{S}_{4}(\mathrm{IV}, \mathrm{IV}, \mathrm{III}, \mathrm{IV})$, with a peroxidic intermediate, in (c). In contrast, the oxidation states are $\mathrm{S}_{4}(\mathrm{IV}, \mathrm{IV}, \mathrm{IV}, \mathrm{IV})$, with an oxyl radical, in (a).

The main differences when comparing the DFT QM/MM S $\mathrm{S}_{3} \rightarrow \mathrm{S}_{4}$ transition to the transition previously proposed by Brudvig and coworkers ${ }^{5,6}$ are (Figures 13 (a) and (d) of the main paper):

1. $M n(4)$ is advanced to the oxidation state $V$ while in (a) the oxidation state of $M n(4)$ remains IV.

2. The $M n=0$ species is proposed in (d) while an oxyl radical is proposed in (a).

3. Double deprotonation of $\mathrm{W}^{\text {fast }}$ and protonation of CP43-R357 is porposed in (d), while single deprotonation of $\mathrm{W}^{\text {fast }}$ is proposed in (a).

4. Hydrogen bonds between $\mathrm{W}^{\text {slow }}$ and the oxo-bridge between $\mathrm{Mn}(3)$ and $\mathrm{Mn}(4)$, and the oxyl radical and CP43-R357 are reinforced in (a) but not in (d).

Finally, several differences can be noted when comparing the DFT-QM/MM structures for the $\mathrm{S}_{4} \rightarrow \mathrm{S}_{0}$ transition (Figure 14(a) of the main paper) to the other proposals. Starting 
the comparison with the structures proposed by Siegbahn,, ${ }^{2,3}$ the main differences are: (see Figures 14 (a) and (b) of the main paper)

1. The $\mathrm{O}_{2}$ forming reaction involves oxo-bridge oxygens in (b), while in (a) the reaction involves deprotonated water molecules attached to $\mathrm{Mn}(4)$ and $\mathrm{Ca}$.

2. The oxygen of a $\mathrm{W}$ ligated to $\mathrm{Mn}(4)$ presumably substitutes $\mathrm{O}(\mathrm{Ca}, \mathrm{Mn}(2), \mathrm{Mn}(3)))$ upon dioxygen formation in (b) while an incoming water molecule substitutes $\mathrm{W}^{\text {slow }}$ in (a).

3. The oxo-bridge between $\mathrm{Mn}(3)$ and $\mathrm{Mn}(4)$ is broken in (b) while it is robust in (a).

4. The broken oxo-bridge oxo is protonated by the $\mathrm{W}$ ligand that substitutes $\mathrm{O}(\mathrm{Ca}, \mathrm{Mn}(2)$, $\mathrm{Mn}(3)))$ becoming $\mathrm{OH}$ ligated to $\mathrm{Mn}(3)$ in (b), while a proton from $\mathrm{W}^{\text {slow }}$ protonates the oxo-bridge between $\mathrm{Mn}(3)$ and $\mathrm{Mn}(4)$ in (a).

5. Protonation of $\mathrm{O}(\mathrm{Mn}(1), \mathrm{Mn}(3), \mathrm{Ca})$ by the $\mathrm{W}$ ligand that substitutes $\mathrm{O}(\mathrm{Ca}, \mathrm{Mn}(2)$, $\mathrm{Mn}(3)))$ in (b), versus protonation of CP43-R357 by $\mathrm{W}^{\text {slow }}$ in (a).

6. $\mathrm{HCO}_{3}^{-}$enters the OEC in (b), while it does not participate in (a).

The main differences when comparing the $\mathrm{S}_{4} \rightarrow \mathrm{S}_{0}$ transition proposed by the DFTQM/MM structural models and the corresponding structures proposed by Messinger ${ }^{4}$ are: (see Figures 14 (a) and (c) of the main paper)

1. The dioxygen forming reaction involves a deprotonated water molecule ligated to $\mathrm{Mn}(4)$ and $\mathrm{O}(\mathrm{Ca}, \mathrm{Mn}(2), \mathrm{Mn}(3))$ in (c), while in (a) the corresponding reaction involves deprotonated water molecules attached to $\mathrm{Mn}(4)$ and $\mathrm{Ca}$. 
2. One unit reduction of the oxidation state of two Mn centers, including $M n(2)$ and $M n(4)$ in (c), while in (a) there is reduction of three Mn-centers, including $\mathrm{Mn}(2), \mathrm{Mn}(3)$ and $\mathrm{Mn}(4)$.

3. Two water molecules enter the OEC, one of which undergoes deprotonation and protonates $\mathrm{O}(\mathrm{Ca}, \mathrm{Mn}(2), \mathrm{Mn}(3))$, in (c). In contrast, only one water molecule enters the OEC in (a), and the oxo-bridge between $\mathrm{Mn}(3)$ and $\mathrm{Mn}(4)$ is protonated by $\mathrm{W}^{\text {slow }}$ in (a).

4. Deprotonation of the OEC results from one of the incoming water molecules in (c), while in (a) the proton is released from $\mathrm{W}^{\text {slow }}$ via CP43-R357.

The main differences when comparing the $\mathrm{S}_{4} \rightarrow \mathrm{S}_{0}$ transition proposed by the DFTQM/MM structural models and the corresponding structures proposed by Brudvig ${ }^{5,6}$ are (see Figures 14 (a) and (d) of the main paper):

1. The dioxygen forming reaction involves nucleophilic attack by $\mathrm{W}^{\text {slow }}$ to $\mathrm{Mn}(4)=\mathrm{O}$ group with proton transfer to an $\mathrm{OH}$ ligand of $\mathrm{Mn}(4)$ in (d) while the corresponding reaction involves a nucleophilic attack of $\mathrm{W}^{\text {slow }}$ to the oxyl radical and proton transfer to oxobridge between $\mathrm{Mn}(3)$ and $\mathrm{Mn}(4)$ in (a).

2. $M n(4)$ is reduced from V to II in (d) while it is reduced from IV to III in (a).

3. $\mathrm{Mn}(2)$ is not reduced in (d) while it is reduced from IV to III in (a).

4. $W^{\text {fast }}$ is substituted by an incoming water molecule in (d) while there is no substitution of $\mathrm{W}^{\text {fast }}$ during this transition in (a). 


\section{Complete reference 36}

Gaussian 03, Revision B.04, Frisch, M. J.; Trucks, G. W.; Schlegel, H. B.; Scuseria, G. E.; Robb, M. A.; Cheeseman, J. R.; Montgomery, Jr., J. A.; Vreven, T.; Kudin, K. N.; Burant, J. C.; Millam, J. M.; Iyengar, S. S.; Tomasi, J.; Barone, V.; Mennucci, B.; Cossi, M.; Scalmani, G.; Rega, N.; Petersson, G. A.; Nakatsuji, H.; Hada, M.; Ehara, M.; Toyota, K.; Fukuda, R.; Hasegawa, J.; Ishida, M.; Nakajima, T.; Honda, Y.; Kitao, O.; Nakai, H.; Klene, M.; Li, X.; Knox, J. E.; Hratchian, H. P.; Cross, J. B.; Bakken, V.; Adamo, C.; Jaramillo, J.; Gomperts, R.; Stratmann, R. E.; Yazyev, O.; Austin, A. J.; Cammi, R.; Pomelli, C.; Ochterski, J. W.; Ayala, P. Y.; Morokuma, K.; Voth, G. A.; Salvador, P.; Dannenberg, J. J.; Zakrzewski, V. G.; Dapprich, S.; Daniels, A. D.; Strain, M. C.; Farkas, O.; Malick, D. K.; Rabuck, A. D.; Raghavachari, K.; Foresman, J. B.; Ortiz, J. V.; Cui, Q.; Baboul, A. G.; Clifford, S.; Cioslowski, J.; Stefanov, B. B.; Liu, G.; Liashenko, A.; Piskorz, P.; Komaromi, I.; Martin, R. L.; Fox, D. J.; Keith, T.; Al-Laham, M. A.; Peng, C. Y.; Nanayakkara, A.; Challacombe, M.; Gill, P. M. W.; Johnson, B.; Chen, W.; Wong, M. W.; Gonzalez, C.; and Pople, J. A.; Gaussian, Inc., Wallingford CT, 2004. 


\section{References}

[1] Ke, B. Photosynthesis: Photobiochemistry and Photobiophysics; Academic Publishers: Dordrecht, 2001.

[2] Siegbahn, P. E. M.; Lundberg, M. Photochem. Photobiol. 2005, 4, 1035-1043.

[3] Siegbahn, P. E. M. Chem. Eur. J. 2006, 12, 9217-9227.

[4] Messinger, J. Phys. Chem. Chem. Phys. 2004, 6, 4764-4771.

[5] McEvoy, J. P.; Brudvig, G. W. Phys. Chem. Chem. Phys. 2004, 6, 4754-4763.

[6] McEvoy, J. P.; Brudvig, G. W. Chemical Reviews 2006, 106, 4455-4483.

[7] Hoganson, C. W.; Babcock, G. T. Science 1997, 277, 1953-1956.

[8] Vrettos, J. S.; Limburg, J.; Brudvig, G. W. Biochim. Biophys. Acta 2001, 1503, 229245.

[9] Roelofs, T. A.; Liang, W. C.; Latimer, M. J.; Cinco, R. M.; Rompel, A.; Andrews, J. C.; Sauer, K.; Yachandra, V. K.; Klein, M. P. Proc. Acad. Sci. USA 1996, 93, 3335-3340.

[10] Yachandra, V. K. Phil. Trans. Roy. Soc. Lond. Series B- Biol. Sci. 2002, 357, 1347-1357.

[11] Robblee, J. H.; Cinco, R. M.; Yachandra, V. K. Biochim. Biophys. Acta 2001, 1503, 7-23.

[12] Siegbahn, P. E. M.; Crabtree, R. H. J. Am. Chem. Soc. 1999, 121, 117-127. 
[13] Siegbahn, P. E. M. Curr. Opin. Chem. Biol. 2002, 6, 227-235.

[14] Dau, H.; luzzolino, L.; Dittmer, J. Biochim. Biophys. Acta 2001, 1503, 24-39.

[15] Yachandra, V. K.; Sauer, K.; Klein, M. P. Chem. Rev. 1996, 96, 2927-2950.

[16] Brudvig, G. W.; Crabtree, R. H. Proc. Natl. Acad. Sci. USA 1986, 83, 4586-4588. 